九州大学学術情報リポジトリ

Kyushu University Institutional Repository

Biology of the Ectoparasitoid Wasp Agrothereutes lanceolatus (Hymenoptera : Ichineumonidae) : Host Acceptance and Larval Development on a Laboratory Host

Ueno, Takatoshi

Institute of Biological Control, Faculty of Agriculture, Kyushu University

https://doi.org/10.5109/24457

出版情報 : 九州大学大学院農学研究院紀要. 47 (1)，pp.37-43，2002-10. Kyushu University バージョン：

権利関係: 


\title{
Biology of the Ectoparasitoid Wasp Agrothereutes lanceolatus (Hymenoptera: Ichneumonidae): Host Acceptance and Larval Development on a Laboratory Host
}

\author{
Takatoshi UENO* \\ Institute of Biological Control, Faculty of Agriculture, Kyushu University, \\ Fukuoka 812-8581, Japan \\ (Received June 28, 2002 and accepted July 12, 2002)
}

\begin{abstract}
Agrothereutes lanceolatus is a common parasitoid attacking several woodland and orchard lepidopteran pests in Japan. This study was undertaken to examine development of $A$. lanceolatus when Galleria mellonella was used as a laboratory host. Both wild-caught and laboratory-reared females readily accepted $G$. mellonella cocoons for attack and oviposition. The percentage successful parasitism was over $80 \%$, suggesting that $G$. mellonella was a very suitable host for $A$. lanceolatus. The parasitoid was a solitary species: Under superparasitism lethal competition among early instars took place, and only one parasitoid developed to an adulthood, although two parasitoid offspring emerged in some exceptional cases. Female $A$. lanceolatus also accepted host cocoons containing pupae of the parasitoid Pimpla nipponica (Ichneumonidae) for oviposition, and the offspring developed successfully as a hyperparasitoid. This suggested that $A$. lanceolatus was a facultative hyperparasitoid.
\end{abstract}

\section{INTRODUCTION}

Agrothereutes lanceolatus Walker is a parasitic wasp distributed in East Asia (Townes et al., 1965). It belongs to the subfamiliy Phygadeuontinae of Ichneumonidae (Hymenoptera). A. lanceolatus is known to attack mature larvae, prepupae and pupae of several tortoricids and pyralids (Lepidoptera), including some important pests such as Chilo suppressalis Walker, Glyphodes pyloalis Walker, and Homona magnanima Diakonoff (Yasumatsu and Watanabe, 1964; Townes et al., 1965; Mao and Kunimi, 1991; Ueno, 1999). Given that A. lanceolatus is a very common parasitoid throughout Japan, it may play an important role in suppressing such lepidopteran pests. However, the potential of $A$. lanceolatus as a natural enemy of these lepidopterous pests is not known. General biology of $A$. lanceolatus also has poorly been investigated so far (Ueno, 1999).

This study is one of a series dealing with bionomics of $A$. lanceolatus and concerns host acceptance and larval development of $A$. lanceolatus. Specifically, experiments were conducted to determine development mode and time of $A$. lanceolatus in the laboratory. Examination of developmental characteristics of the parasitoid would provide essential information about the basic biology of $A$. lanceolatus.

Suitability of a factitious host was also assessed for rearing of $A$. lanceolatus. Given that natural hosts of $A$. lanceolatus are difficult to mass-rear in the laboratory, use of a factitious host would be ideal for rearing the parasitoid. Therefore, in this study, Galleria mellonella (L.) (Lepidoptera: Pyralidae) was used as a candidate laboratory host. $G$.

\footnotetext{
*E-mail: ueno@grt.kyushu-u.ac.jp
} 
mellonella was selected because it is easy to mass-rear and because it is known as a suitable laboratory host for a number of ichneumonid parasitoids (e.g. Sandlan, 1982; Ueno and Tanaka, 1994). Thus, acceptability of $G$. mellonella for A. lanceolatus and parasitoid offspring survival on $G$. mellonella were examined to assess host suitability.

\section{MATERIALS AND METHODS}

\section{Insect cultures and general methods}

A culture of $A$. lanceolatus was established in the laboratory from adult parasitoids collected in the campus of Nagoya University, central Japan and Fukuoka city, Kyushu, Japan. Cocoons containing prepupae of Galleria mellonella (L.) (Lepidoptera: Pyralidae) were used as a laboratory host to rear the parasitoid.

Newly emerged female parasitoids were placed in plastic cups $(10 \mathrm{~cm}$ in diameter, 4.5 $\mathrm{cm}$ in height) and were paired with males. Adult parasitoids were provided with a honey solution in tissue papers placed in the cups, and the papers were replaced twice a week. The colony was maintained at constant $20^{\circ} \mathrm{C}$ and a photoperiod of $16 \mathrm{~L}: 8 \mathrm{D}$.

For all experiments, laboratory-reared female parasitoids (F2 or F3) were selected for similarity in size and were $6-7$ days old unless otherwise stated. $G$. mellonella larvae were reared on an artificial diet at $30-33^{\circ} \mathrm{C}$, and the cocoons containing prepupae were used in experiments.

\section{Host acceptability}

The aim of this experiment was to examine whether $G$. mellonella was accepted as host. For this purpose, wild-caught female A. lanceolatus was provided with $G$. mellonella cocoons, and females' response to the cocoon was observed. Response by laboratory-reared female parasitoids was also observed. Parasitoids collected at Nagoya and Fukuoka (see above) were used for testing. The age of wild-caught females was unknown, and they were used for testing 2-3 days after collection. One day before test, both wild-caught and laboratory-reared females were allowed access two host cocoons for $30 \mathrm{~min}$.

Each female parasitoid in the cup was provided with two host cocoons, and the behavioral response was continuously observed. When a female encountered a host cocoon, her response was carefully observed and noted. When hosts were attacked, whether a female oviposited on, or rejected, a host after drilling into the host was confirmed by observing the base of her ovipositor under a binocular microscope. It is possible to see an egg passing through the base of the ovipositor of $A$. lanceolatus during oviposition under a binocular microscope, as with other ichneumonid wasps (Quicke, 1997). Hosts attacked by $A$. lanceolatus were dissected to examine where eggs were placed (i.e. on host body surface or within host body).

\section{Larval development}

This experiment was designed to examine offspring parasitoid development. Host cocoons were singly offered for female parasitoids and were observed for single parasitism. Parasitized hosts were collected and were placed singly in plastic cups $(4.5 \mathrm{~cm}$ in diameter, $3.0 \mathrm{~cm}$ in height). The cups were kept at constant $25^{\circ} \mathrm{C}$ and a photoperiod of 
16L:8D. Daily observations were made at $24 \mathrm{~h}$ intervals to check the day of emergence of parasitoid offspring.

\section{Superparasitism and larval competition}

This experiment was conducted to examine the results of multiple egg deposition on single host individuals in parasitoid development. Fresh host cocoons were singly presented to female parasitoids for oviposition. After single oviposition on each host cocoon had been confirmed, the cocoon was removed and was presented to another female parasitoid for superparasitism after $1-3 \mathrm{~min}$ of the first parasitism. When the second oviposition (=superparasitism) was confirmed, host cocoons superparasitized were used for the experiment. Superparasitized hosts were placed singly in plastic cups $(4.5 \mathrm{~cm}$ in diameter, $3.0 \mathrm{~cm}$ in height) and were kept at $25 \pm 0.5^{\circ} \mathrm{C}$ with a photoperiod of 16L:8D for parasitoid emergence. The day that parasitoids emerged was recorded. Hosts were kept up to 20-25 days since parasitism, and those that had not produced any parasitoids were dissected under a binocular microscope.

\section{Facultative hyperparasitism}

Test was conducted to assess whether $A$. lanceolatus could be a facultative hyperparasitoid. For this purpose, G. mellonella cocoons parasitized by a primary parasitoid were offered to female $A$. lanceolatus and its response to the cocoons was observed. When cocoons were hyperparasitized, the cocoons were reared as mentioned above.

As a primary parasitoid, the solitary pupal endoparasitoid Pimpla nipponica Uchida (Ichneumonidae), which is commonly found to coexist with A. lanceolatus, was used. Host cocoons containing pupae were allowed to be parasitized by $P$. nipponica, and were used for testing when $P$. nipponica was at the pupal stage.

\section{Data analysis}

Analysis of variance (ANOVA) was applied to examine effect of the parasitoid sex on parasitoid development time. Other data were analyzed with chi-squared tests. JMP (SAS Institute, 1997) was used for statistical analyses.

\section{RESULTS AND DISCUSSION}

\section{Host acceptability}

Because natural hosts used by $A$. lanceolatus are difficult to mass-rear, an alternative host for laboratory-rearing of $A$. lanceolatus is required. In the present study, $G$. mellonella was used as a candidate laboratory host, testing its suitability for rearing the parasitoid. The results demonstrated that it was readily accepted by $A$. lanceolatus for attack and oviposition (Table 1).

Wild-caught $A$. lanceolatus recognized and attacked host cocoons presented. Host cocoons once attacked were mostly parasitized (Table 1), and each parasitized host received only one parasitoid egg. Parasitoid eggs were found on the surface of host prepupae within the cocoons. Occasionally hosts were used for host-feeding.

Likewise, most laboratory-reared females accepted $G$. mellonella cocoons for oviposition (Table 1). Female A. lanceolatus laid one egg on each host. No difference 
Table 1. Acceptability of a factitious laboratory host, $G$. mellonella, for wild-caught and laboratory-reared $A$. lanceolatus

\begin{tabular}{llccc}
\hline Generation & Strain & N of fernales & \% attacked* & \% oviposited* \\
\hline Wild-caught & Nagoya & 12 & 87.5 & 100 \\
Reared & Nagoya & 20 & 97.5 & 92.3 \\
Wild-caught & Fukuoka & 7 & 100 & 92.9 \\
Reared & Fukuoka & 13 & 100 & 96.2 \\
\hline
\end{tabular}

* \% of hosts attacked=Number of hosts probed with the ovipositor/Total number of hosts given to each female parasitoid. \% of hosts oviposited=Number of hosts oviposited/Number of hosts attacked by female parasitoids. No significant difference was detected in the percentages of hosts attacked or oviposited (chi-squared test, $\mathrm{P}>0.05$ ). All parasitized (=oviposited) hosts received one egg with no exception.

was found in the percentages attack and oviposition depending on parasitoid generations and localities from which $A$. lanceolatus was originated (Table 1).

Although $G$. mellonella was not a natural host for A. lanceolatus, the female readily recognized and attacked it. This may be because $G$. mellonella cocoons share some of host cues that are used by $A$. lanceolatus for host recognition. A likely cue that is in common could be the morphology of 'cocoon'. Parasitoids use a combination of different cues to recognize their host, and host physical features are among the cues (Vinson, 1976; Arthur, 1981; Quicke, 1997).

Some ichneumonid parasitoids of Lepidoptera attack artificial hosts that morphologically mimic insect 'cocoons' (e.g. Henaut and Guerdoux, 1982). Likewise, the ichneumonid A. lanceolatus shows an interest in a white paper tube or cotton pad, which mimics a 'cocoon', and often probes such a tube or pad with the ovipositor (Ueno, unpublished). This suggests that $A$. lanceolatus uses at least in part physical cues that are in common among insect cocoons, to recognize the host. Although $G$. mellonella is a factitious host, the morphology of the cocoons itself may cause ovipositor probing by $A$. lanceolatus.

\section{Larval development}

Parasitized G. mellonella cocoons mostly produced offspring A. lanceolatus (parasitoid production $>80 \%$ ) indicating that $G$. mellonella was highly suitable for $A$. lanceolatus larval development (Table 2). With no exception, A. lanceolatus developed

Table 2. Host suitability of a factitious laboratory host, $G$. mellonella, for A. lanceolatus

\begin{tabular}{lccl}
\hline Strain & N of hosts & $\begin{array}{l}\text { \% hosts producing } \\
\text { parasitoids* }\end{array}$ & $\begin{array}{l}\text { Developmental } \\
\text { mode of parasitoids }\end{array}$ \\
\hline Nagoya & 108 & 80.6 & Ectoparasitic \\
Fukuoka & 56 & 83.9 & Ectoparasitic \\
\hline
\end{tabular}

* No significant difference was detected in the percentages of hosts producing parasitoid offspring ( $=$ offspring survival) between the strains of $A$. lanceolatus (chi-squared test, $\mathrm{P}>0.05)$. 
as an ectoparasitoid, feeding on host prepupae from external positions of the hosts (Table 2).

The results showed that a factitious host, $G$. mellonella, is highly suitable for rearing of $A$. lanceolatus in terms of acceptability to the adult female (Table 1) and offspring production (Table 2). G. mellonella is widely recognized as a good laboratory host for rearing a number of parasitoids (e.g. Sandlan, 1982; Ueno and Tanaka, 1994), and this is the case for $A$. lanceolatus. The results also have confirmed that $A$. lanceolatus is an ectoparasitoid wasp like other members of Phygadeuontinae of Ichneumonidae.

Male wasps had a mean development time of $14.70 \pm 0.17$ ( $\pm \mathrm{SE}$ ) days with values ranging 13 to 19 days. Female development time ranged from 15 to 18 days with a mean of $16.12 \pm 0.18$ ( $\pm \mathrm{SE}$ ) days. ANOVA revealed that males developed significantly faster than females $(\mathrm{N}=70, \mathrm{df}=2, F=31.10, P<0.0001)$ (Table 3). Faster development in male parasitoids than females has widely been reported for many parasitoids (Ueno and Tanaka, 1994; Quicke, 1997).

Table 3. Development time of male and female A. lanceolatus (Nagoya strain) when reared on $G$. mellonella

\begin{tabular}{llc}
\hline Sex of parasitoids & N & Development time (day) $^{*}$ \\
\hline Male & 37 & $14.7 \pm 0.17$ \\
Female & 33 & $16.1 \pm 0.18$ \\
\hline
\end{tabular}

* Data were shown as mean $\pm \mathrm{SE}$. Females required significantly more time to complete the development (from egg to emergence) than males (ANOVA, $\mathrm{P}<$ 0.0001 ).

\section{Superparasitism and larval competition}

The results confirmed that $A$. lanceolatus was a solitary species (Table 4); even when two eggs were laid on a single host individual, only one parasitoid matured and developed to an adulthood. Offspring survival was not reduced due to superparasitism (Table 4). Dissection of superparasitized hosts after parasitoid emergence suggested that one immature parasitoid died mostly during its early stages of development (i.e. egg or first instar). Competition between two developing $A$. lanceolatus may occur within the early stages at least when superparasitism (i.e. the second parasitism) takes place shortly after the first parasitism. This pattern of larval competition is frequently observed for a number of solitary parasitoids (Mackauer, 1990; Quicke, 1997).

In solitary parasitoids, two or more immature parasitoids rarely developed to middle or late instars; only one winner of competition can develop to a middle instar or more, and losers died mostly during egg or first instar stage (Mackauer, 1990). In A. lanceolatus, however, there were four cases in which two middle instar larvae died. This suggested that scramble rather than context competition could occasionally occur, though context type competition during the early stage of development is the general rule.

In two cases, successful superparasitism was found; two parasitoid offspring emerged from a single host individual (Table 4). In endoparasitoid wasps successful superpara- 
Table 4. Effect of superparasitism on production of parasitoid offspring in A. lanceolatus

\begin{tabular}{lcccc}
\hline Parasitism & N & \% offspring survival* & $\begin{array}{l}\text { \% multiple parasitoid } \\
\text { production }^{* *}\end{array}$ \\
\hline Single & 48 & 79.2 & - \\
Superparasitism & 68 & 75.0 & 3.9 \\
\hline
\end{tabular}

* There was no significant difference in the percentages (chi-squared test, $\mathrm{P}>$ $0.05)$.

** Percentage of hosts that produced two parasitoid offspring.

sitism is extremely rare while in ectoparasitoid wasps successful superparasitism occasionally takes place. Factors causing this difference are not known. Mechanism and process of competition might differ between ecto- and endoparasitoids.

\section{Hyperparasitism}

Members of the genus Agrothereutes belonging to Phygadeuontinae are known as primary ectoparasitoids, attacking principally Lepidoptera (Townes et al., 1965). However, at least some of them may also be facultative hyperparasitoids (Shiotsu and Arakawa, 1982).

In the present paper, a laboratory experiment was conducted to examine whether $A$. lanceolatus could be a facultative hyperparasitoid. The experiment has revealed that $A$. lanceolatus attacks and oviposits on pupae of the primary endoparasitoid Pimpla nipponica within host pupae and is able to develop successfully (Table 5). This is the first experimental evidence that Agrothereutes species can be a hyperparasitoid of other hymenopterans. Although host records suggest this parasitoid is a primary parasitoid of Lepidoptera (Yasumatsu and Watanabe, 1964; Townes et al., 1965), the potential host range could be wider due to facultative hyperparasitism.

Table 5. Facultative hyperparasitism by $A$. lanceolatus

\begin{tabular}{lccc}
\hline Host & N & \% parasitized * & \% offspring production * \\
\hline G. mellonella & 25 & 96.0 & 83.3 \\
$P$. nipponica** & 23 & 82.6 & 73.7 \\
\hline
\end{tabular}

* No significant difference was detected between the groups (chi-squared test, $\mathrm{P}>$ 0.05).

** Pupa of the ichneumonid endoparasitoid $P$. nipponica within $G$. mellonella pupa enclosed in the cocoon was used for testing.

\section{REFERENCES}

Arthur, A. P. 1981 Host acceptance by parasitoids. In "Semiochemicals, their Role in Pest Control", ed. by D. A. Nordlund, R. L. Jones and W. J. Lewis, Wiley, New York, pp. 97-120

Henaut, A. and J. L. Guerdoux 1982 Location of a lure by the drumming insect Pimpla instigator. 
Experimentia, 38: $346-347$

Mackauer, M. 1990 Host discrimination and larval competition in solitary endoparasitoids. In "Critical issues in biological control", ed. by M. Mackauer, L. E. Eller and J. Roland, Intercept, Andover, pp. 41-62

Mao, H. and Y. Kunimi 1991 Pupal mortality of the oriental tea tortrix, Homona magnanima Diakonoff (Lepidoptera: Tortricidae), caused by parasitoids and pathogens. Jap. J. Appl. Entomol. Zool., 35: $241-245$

Quicke, D. L. J. 1997 Parasitic wasps. Chapman \& Hall, London

Sandlan, K. 1982 Host suitability and its effects on biology in Coccygomimus turionellae (Hymenoptera: Ichneumonidae). Ann. Entomol. Soc. Am., 75: 217-221

SAS Institute 1997 JMP user's guide, version 3.1. SAS Institute, Cary, NC.

Shiotsu, Y. and R. Arakawa 1982 One host-one parasitoid system: seasonal life cycles of Pryeria sinica (Lepidoptera) and Agrothereutes minousubae (Hymenoptera). Res. Popul. Ecol., 24: 43-57

Townes, H., S. Momoi, and M. Townes 1965 A catalogue and reclassification of the Eastern Palearctic Ichneumonidae. Mem. Am. Entomol. Inst. 5

Ueno, T. 1999 Adult size and reproduction in the ectoparasitoid Agrothereutes lanceolatus Walker (Hym., Ichneumonidae). J. Appl. Entomol., 123: 357-362

Ueno, T. and T. Tanaka 1994 Comparative biology of six polyphagous solitary pupal endoparasitoids (Hymenoptera: Ichneumonidae): differential host suitability and sex allocation. Ann. Entornol. Soc. Am. 87: 592-598

Vinson, S. B. 1976 Host selection by insect parasitoids. Ann. Rev. Entomol., 21: 109-133

Vinson, S. B. and G. F. Iwantsch 1980 Host suitability for insect parasitoids. Ann. Rev. Entomol., 25: $397-419$

Yasumatsu, K. and C. Watanabe 1964 A tentative catalogue of insect natural enemies of injurious insects in Japan. Part 1. Host parasite-predator catalogue. Entomol. Lab., Fac. Agric., Kyushu Univ., Fukuoka 